\title{
Teaching Mode of Mechanical Design Course based on Simulation Analysis Technology
}

\author{
https://doi.org/10.3991/ijet.v12i07.7221 \\ Xueyi $\mathrm{Li}^{*}$ \\ Shandong University of Science and Technology, Qingdao, China \\ lixueyio7etsinghua.org.cn \\ Junying Wei \\ Shandong University of Science and Technology, Qingdao, China \\ Shuhui Ding \\ Shandong University of Science and Technology, Qingdao, China \\ Quanwei Wang \\ Shandong University of Science and Technology, Qingdao, China
}

\begin{abstract}
Mechanical design course covers various contents, and most of them are complex theoretical knowledge. However, current teaching modes in China mainly combine textbook with PPT (PowerPoint) created in advance. This monotonous mode cause students to lose interests in their curriculum, and knowledge becomes difficult to gain. To improve teaching effectiveness, we propose a novel teaching mode by applying simulation technology to a particular mechanical design course. Using the chapter of gear transmission as an example, we also introduce a specific approach. Comparing traditional modes with the proposed mode, we demonstrate that combining simulation analysis technology with the content of mechanical design course can enrich the teaching process and improve students' learning interests. The proposed approach can also help students analyze and solve problems with relevant knowledge and enhance their practical abilities. Thus, these students can satisfy the requirements of modern society for mechanical engineering graduates.
\end{abstract}

Keywords-Mechanical design course, Teaching mode, Reform, Teaching effectiveness

\section{Introduction}

Mechanical design is a key course requiring mastery from students of mechanical engineering and related majors. The course mainly introduces the basic design method of mechanical parts, design theory of mechanisms, and proper methods of using standard and technical documents. The mechanical design course is also comprehensive, and it plays an important role in the entire teaching system. Learning this course can provide a review of some previously completed basic courses and establish the 
foundation for further studies on related professional courses and work [1]. Therefore, the teaching effectiveness of this course should be improved to enhance the professional skills of students and train them to become qualified engineers.

In China, the current teaching mode of mechanical design is relatively monotonous, and its main approach involves teaching theory in textbooks combined with PPT (PowerPoint). However, the knowledge of mechanical design is complicated, and this type of traditional teaching mode is not closely related to practical applications. Moreover, students show a lack of interests in classes. With extensive applications of simulation technology in the actual process of production design, employers impose higher requirements for graduates in computer-aided technology. Some experts, such as Le [2], emphasized that mechanical engineering education is transforming from teaching theory into practical applications, and they believed that the teaching mode, which is combined with theoretical teaching, simulation technology, and engineering practices, is the optimum technique to adapt to current teaching environment. Nevertheless, computer-aided technology courses in the undergraduate training system of mechanical engineering and related professions are taught for a few hours, and contents are simple. In the later mechanical design course, students basically fail to apply simulation technology to relevant contents. Thus, this type of teaching mode that creates no connections among different courses forms a complete system of knowledge scarcely. This system may also cause students to lose the ability to integrate and apply knowledge. Hence, improving teaching effectiveness is a key issue for researchers to help students master their professional skills and enhance their competitiveness.

\section{State of Art}

Numerous experts in the field of mechanical engineering proposed their views on improving the teaching effectiveness in mechanical design. Cohen et al. [3] introduced a "Design and Manufacture Laboratory," which is intended for senior undergraduate students. Using this laboratory, students can gain professional skills and enhance their abilities, such as team cooperation, time management, and selfmanagement. However, Cohen et al. [3] disregarded the importance of improving class teaching quality. At the University of British Columbia, traditional lecture-based modes were converted into a team-based learning format, and a new course (MECH325) was developed [4]. The contents of the developed course are genuinely rich, and this course covers the learning performance of mechanical parts and the process of using and selecting them. Since the teaching format was converted, students' test scores and teaching effectiveness evaluation have improved. To familiarize students with modern design methods and techniques, other researchers developed "The Karlsruhe Education Model for Product Development" for mechanical design teaching [5], and this education model can improve students' application abilities. However, these methods are unsuitable for the teaching environment in China. Moreover, Xu et al. [6] found that applying MATLAB to the mechanical design course can promote students' learning interests in the course and help them learn other modern 
technology topics. Furthermore, some researchers [7,8] showed that adding digital models to mechanical design classes can vividly display mechanisms to students and thus enrich the teaching content and improve the teaching quality. However, they failed to consider the importance of guiding students to learn and solve problems after class.

Some experts, such as Beckmann [9], thought that practical experience is significant to the research and development of products, but obtaining practical experience in the teaching process is difficult. Establishing a connection between a mechanical design course and practices can compensate for this defect and enhance the comprehensive ability and learning activity of students. Accordingly, Fujii et al. [10] provided a training program to achieve advanced 3D-CAD skills, which can strengthen cooperation between schools and enterprises and consequently enrich students' practical experiences. Although some disadvantages in the lecture process have been overcame by the curriculum project of the mechanical design course in our country, further improvements in the ability to apply modern techniques to solve problems should be obtained.

In this study, a novel teaching mode is proposed on the basis of previous studies to address problems related to the mechanical design course in China by integrating simulation technology with the course. Combining modern technology and traditional theoretical knowledge can enrich the teaching content and improve the students' learning interests. The proposed method can help teachers share their scientific knowledge and skills with students in time and develop the students' abilities to explore and solve problems. The proposed method is described in detail in the following sections.

\section{$3 \quad$ Methodology}

Computer simulation technology includes two parts, namely, modeling and simulation analyses. In general, students have learned 3D modeling and simulation software before they study the mechanical design course, and it provides a basis for the novel teaching mode. The main contents of mechanical design course are shown in Fig. 1.

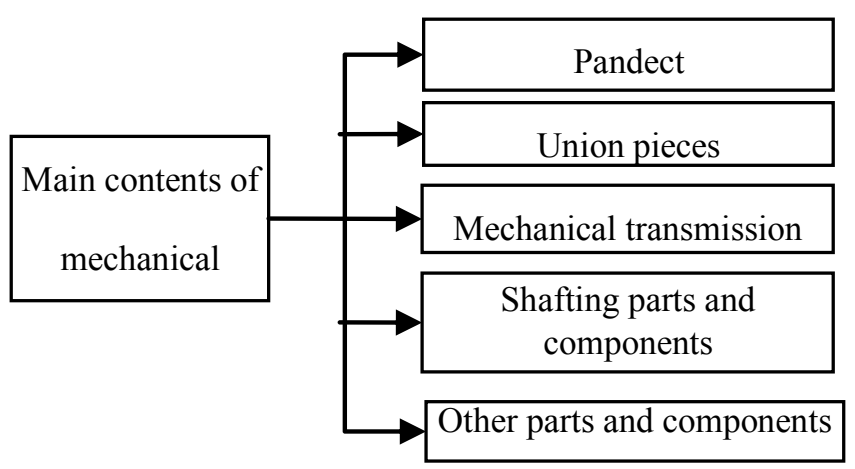

Fig. 1. Main contents of mechanical design 
Limited to teaching hours, several key chapters in the mechanical design course focus on adding computer simulation technology to provide students with an enhanced understanding of relevant knowledge. In addition, teachers must prepare relevant materials before classes, which may be significantly challenging to them. Moreover, a specific method of applying computer simulation technology to the part of the union pieces is illustrated as Fig. 2.

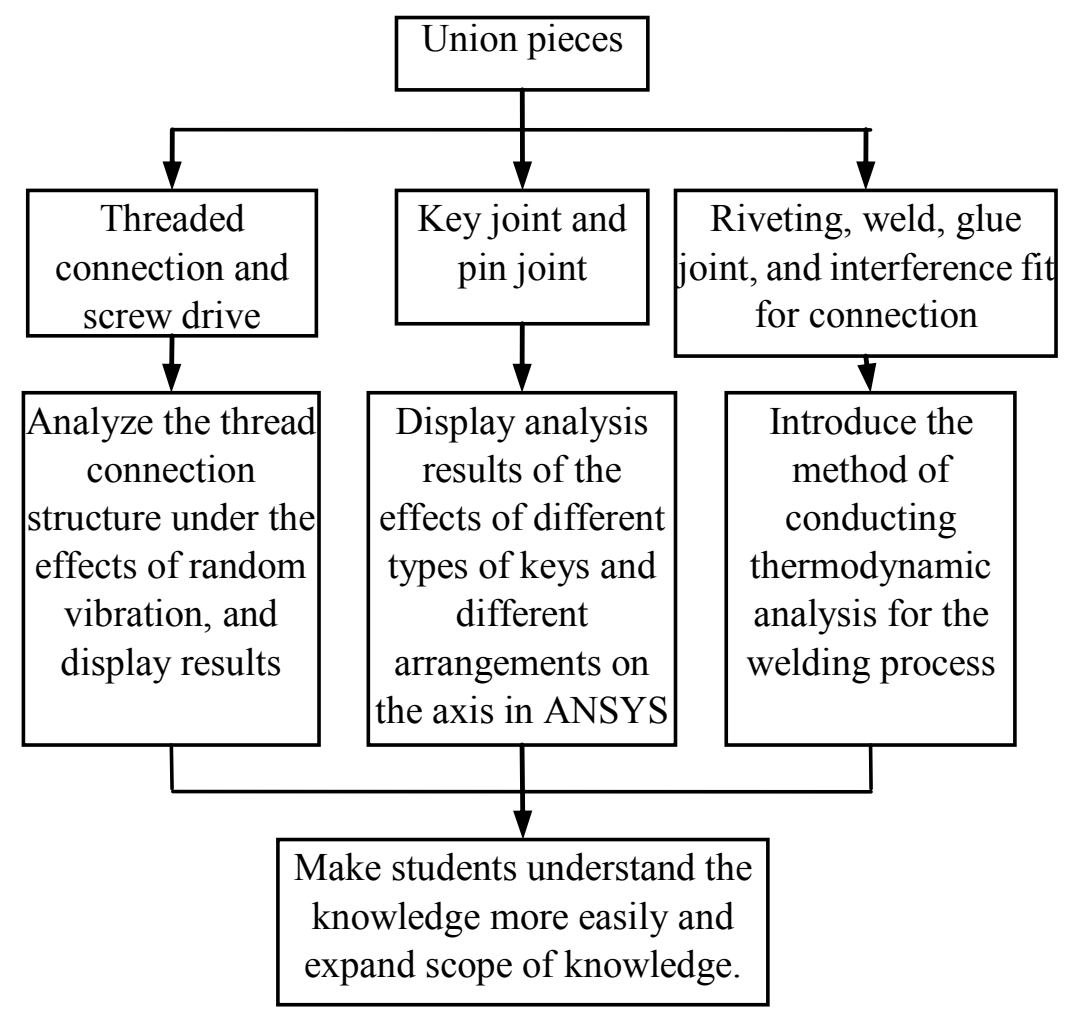

Fig. 2. Reform idea for teaching content of union pieces

Mechanical union pieces, such as bolts, keys, and other parts, are standard components, and appropriate sizes of these components are usually chosen on the basis of actual conditions during mechanical designing. Therefore, students are not required to master technology for the simulation of these components.

Furthermore, a specific method of applying computer simulation technology to the part of mechanical transmission is shown as Fig. 3.

The content of this part is a key element will be involved in a curriculum project, graduation project, and future work life; students are required to master this part. Hence, teachers should encourage students to conduct simulation analysis for mechanisms in this part after classes as well as lay the foundation for later study and work.

The specific method to apply simulation technology to shafting parts and components is shown in Fig. 4. 


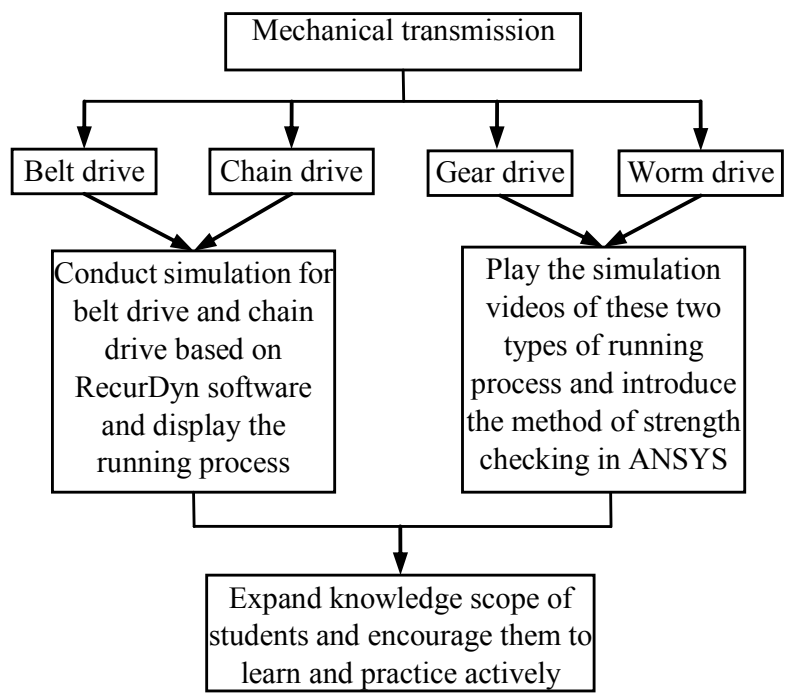

Fig. 3. Reform idea for the teaching content of mechanical transmission

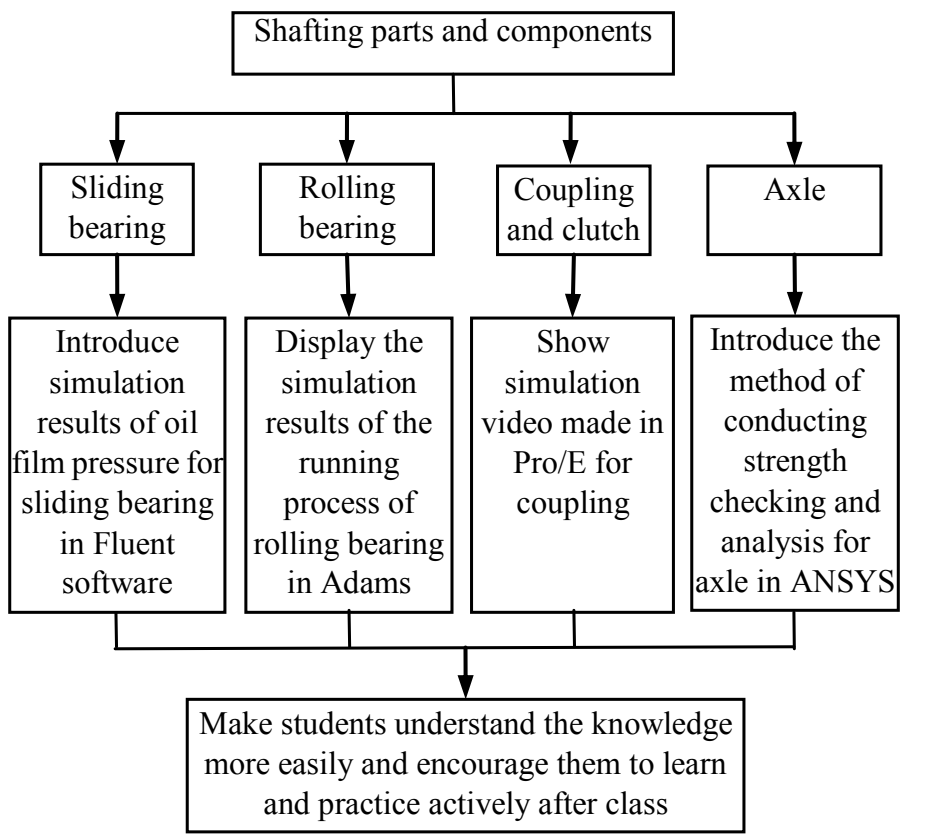

Fig. 4. Reform idea for the teaching content of shafting parts and components

Adding simulation technology to the teaching process of shafting parts and components not only can enrich the teaching content, make students understand more easily, but also encourage students to check the strength and conduct analyses for commonly used components. 
The teaching staff can arrange these simulation parts to the introductions in every chapter or view them as extensional knowledge; then, they can play PPT or video of the simulation to students. These techniques can enrich the teaching contents. Moreover, students should be encouraged to master the knowledge and analyze as well as solve problems actively using relevant software. Analytical process and results can be demonstrated in the form of a paper or report. In addition, students who use simulation technology to check the strength of the designed shaft or gear can obtain extra marks during the curriculum project. These approaches will improve learning activity and practical ability.

The reformed teaching mode not only can enrich the teaching contents, improve learning activities of students, but also can allow students to gain contact with modern technology and adapt them to the development of modern society. Encouraging students to conduct simulation analysis based on knowledge gained actively can compensate for the limitations of the lack of practice in the traditional teaching mode and enable students to satisfy the requirements of modern enterprises for technicians.

\section{$4 \quad$ Teaching Case and Effectiveness}

\subsection{Teaching case}

Gear transmission is a significant part of teaching contents in the mechanical design course, and the details of applying a reformed mode in this part are introduced. The specific teaching idea in this part is presented in Fig. 5.

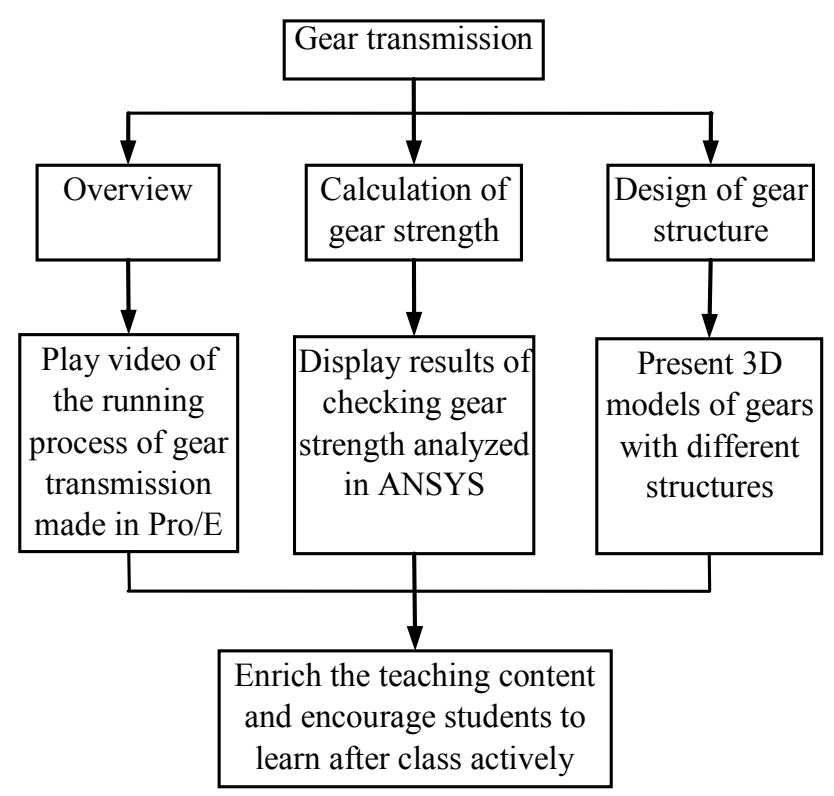

Fig. 5. Teaching idea of the chapter on gear transmission 
Based on the idea, a 3D model of a pair of gears can be created in Pro/E, conducting motion simulation for it. When presenting a lesson regarding the overview of gear transmission, teachers can play simulation videos as part of the introduction. In later lessons, such as calculating parameters of gears and designing, model pictures can be used to create a lively teaching process. In addition, students can also be encouraged to conduct simulation by themselves after class. Moreover, one of the model pictures is presented as Fig. 6 .

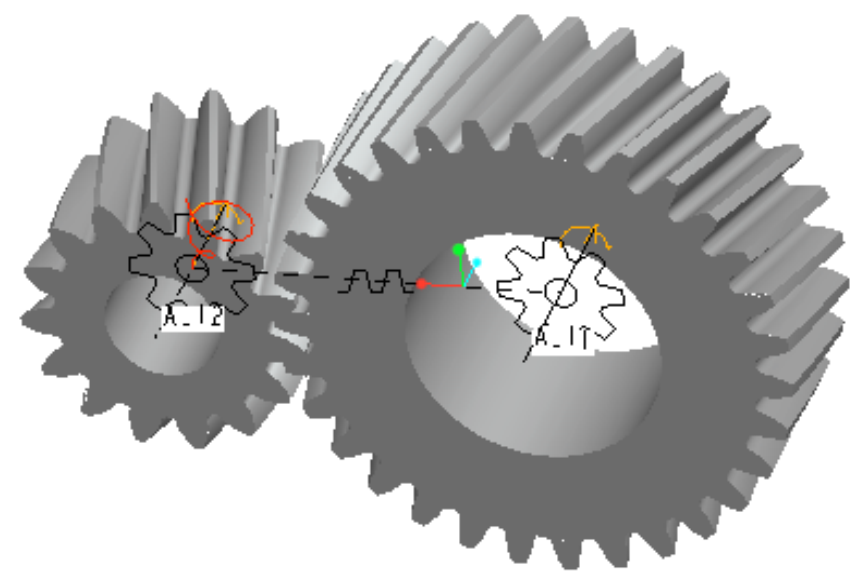

Fig. 6. Model picture of gear transmission

After learning theory of gear design and calculating strength, students will know how to design gear transmission under the condition of satisfying contact fatigue strength of the tooth surface and bending fatigue strength of the tooth root. Then, students will recheck the strength of the designed gear transmission. Performing transient meshing analysis for gear pair using finite element analysis technology, three worst meshing positions can be found with weak tooth contact and root bending fatigue strength [11]. Then, fatigue analyses can be conducted at these three meshing positions, and gear strength can be checked in a computer. Teachers should introduce the method on the process of conducting simulation analysis to check the strength of gear transmission to students, and it can serve as an extension of knowledge in textbooks. In this manner, the combination of traditional theory teaching with modern technology is generated. Details of this combination are described later.

In the transient meshing analysis for gear transmission, mesh model of a gear pair should be built prior to analysis (Fig. 7). If analysis is completed, three worst meshing positions can be found with weak tooth contact and root bending fatigue strength. Performing fatigue analyses for gear transmission at these three positions respectively using Workbench software. Furthermore, analyses results are shown respectively in Fig. 8, and they all meet the strength requirements. This part is introduced as extension, and students are encouraged to conduct analysis after class. Consequently, they will gain better mastery of the knowledge of gear transmission design and strength checking. 


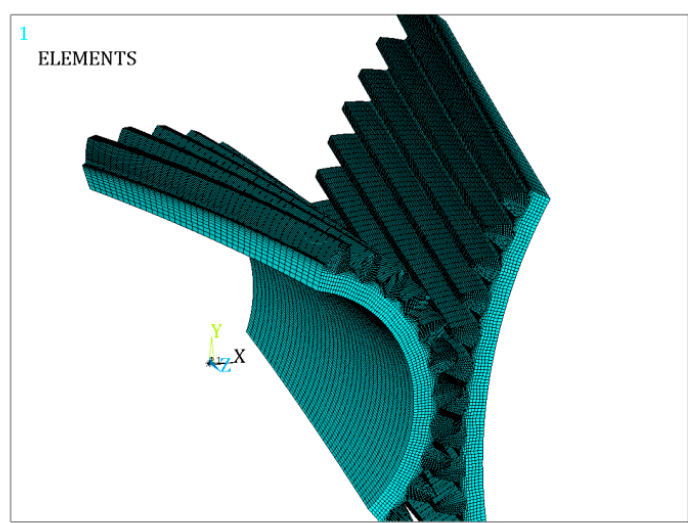

Fig. 7. Mesh model of gear transmission

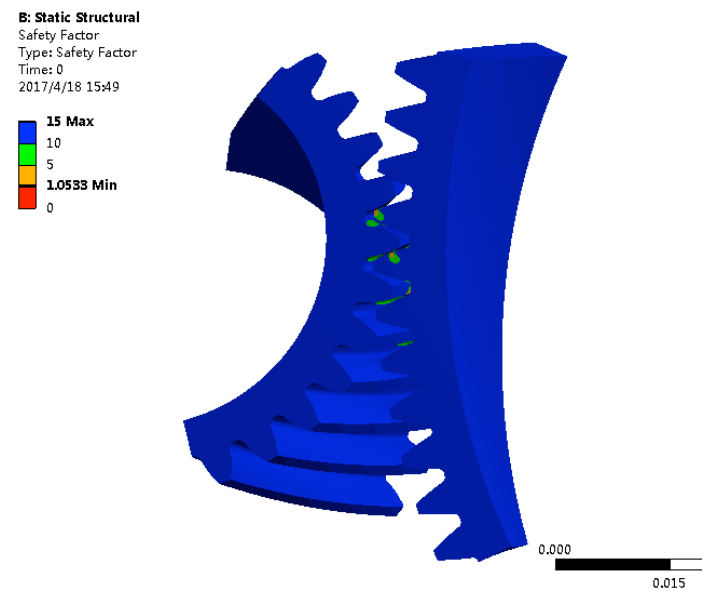

a) Result of tooth contact fatigue analysis

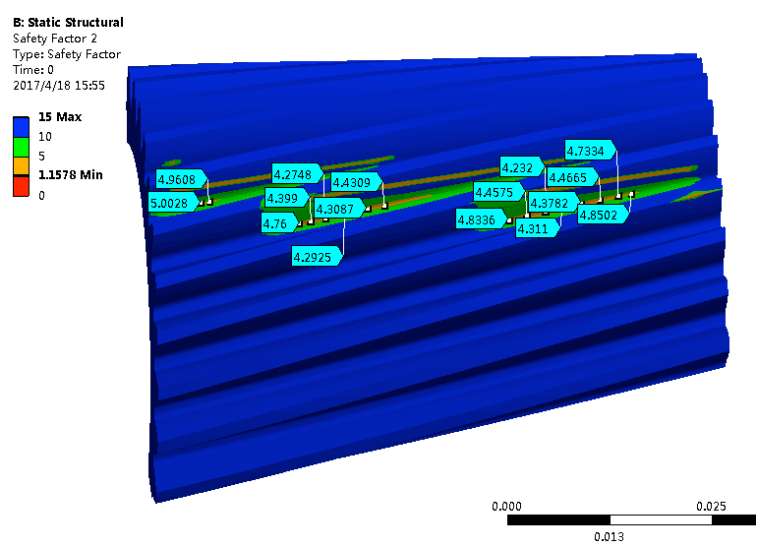

b) Result of root bending fatigue analysis of drive gear 


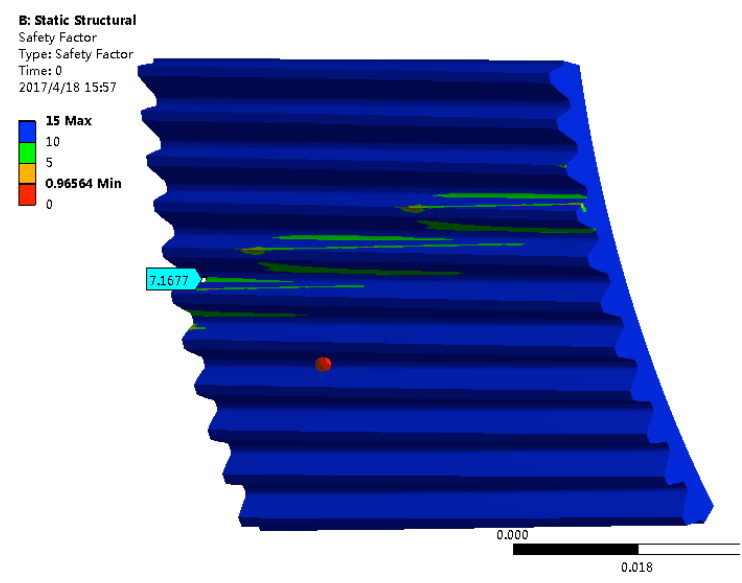

c) Result of root bending fatigue analysis of a driven gear

Fig. 8. Results of fatigue analyses for gear transmission

After learning the designing structure for gears, students will know how to select appropriate structures for gears and how to determine the geometric sizes of gear ring, spoke, and so on. In addition, 3D models of different gears with different structures can be established, which are presented in Fig. 9.

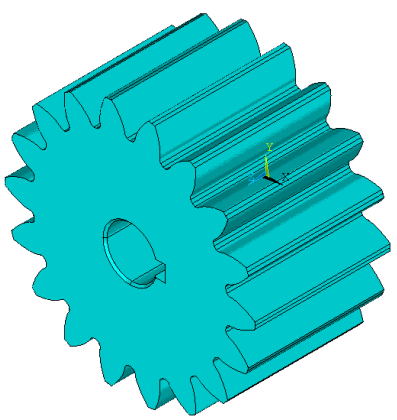

a) Solid structure

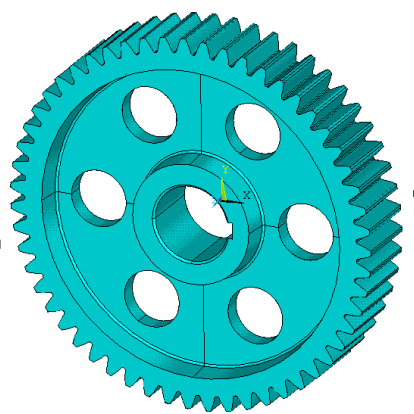

b) Web plate structure

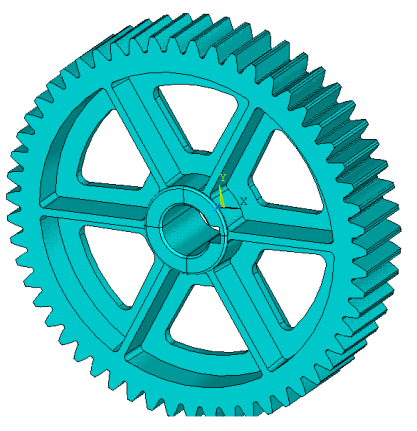

c) Spoke structure

Fig. 9. Gear models with different structures

Students are encouraged to summarize their learning experiences and achievements in the form of papers or reports after completing lessons on gear transmission. This teaching mode will help them gain mastery of the knowledge in this chapter and improve the ability to analyze and solve problems.

\subsection{Effectiveness}

Based on the actual teaching situation of the mechanical course in our university, the reformed teaching mode has been proposed and conducted since 2012. Conse- 
quently, students who entered the school before 2012 were brought up using the traditional teaching mode, whereas students who entered the school after 2012 were brought up based on the new reformed mode. When mechanical design lessons were finished completely, questionnaire surveys were distributed to students who entered the school in 2011 and 2012, respectively. In addition, the survey seeks to know whether teaching content was plentiful or not, the situation of students' learning interests, and so on. Moreover, the completion rate of the extra mission in the curriculum project and the rate of good grades of the graduation thesis were summarized for these students. A questionnaire survey was made to enterprises concerning satisfaction degrees of graduate performances on the interview and later work. Results of all these follow-up surveys are organized and presented as Fig. 10.

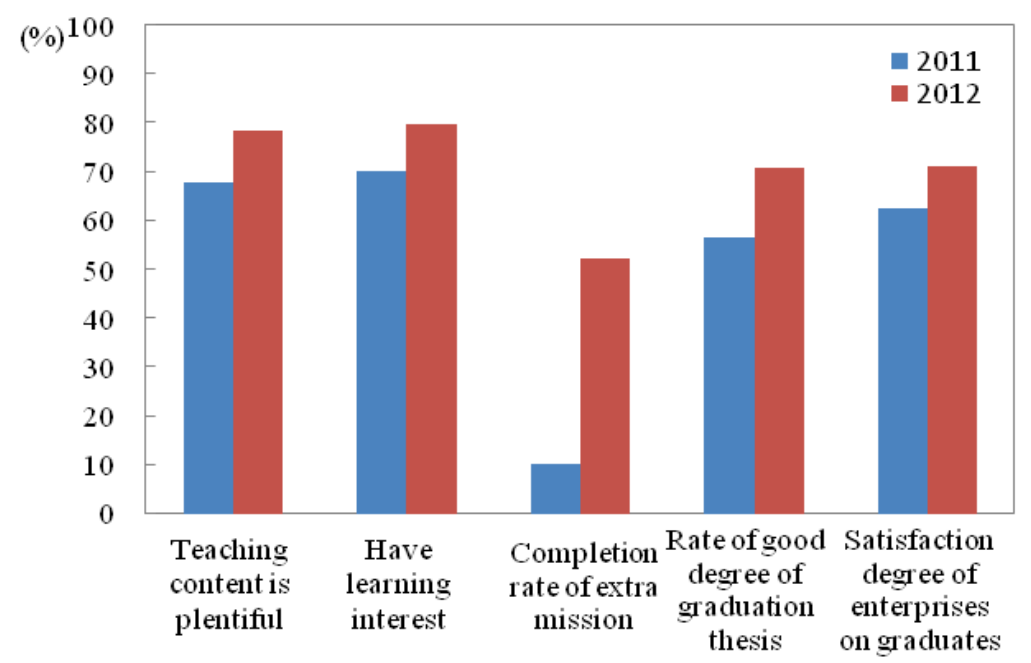

Fig. 10. Results of surveys

Each item of students in Grade 2012 is better than that of students in Grade 2011 (Fig. 10). Survey's feedback from students demonstrates that they thought the teaching content was more plentiful and easy-to-understand in the reformed teaching mode. Furthermore, students' learning interests were improved. Especially in the aspect of completion rate of the extra mission in the curriculum project, the rate of students in Grade 2012 is much higher than that of students in Grade 2011. The results show that students' activities of conducting simulation technology to solve engineering problems and practical abilities were improved. In addition, from the rate of good degree of graduation thesis and satisfaction degree of enterprises, the reformed mode of adding modern simulation technology into mechanical design teaching totally achieved the purpose of reforming the traditional teaching mode. Students who were trained in the reformed mode can combine the modern simulation technology with knowledge in textbooks as well as basically meet the requirements of enterprises to graduates. 


\section{Conclusions}

Comparing the traditional teaching mode with reformed teaching mode, we found that the reformed teaching mode based on simulation technology can compensate for the limitations of the traditional mode and consequently improve teaching quality. In addition, specific performances are summarized as follows:

1. Using the reformed teaching mode can improve students' interests and improve learning activities after class. Moreover, students can fully integrate knowledge they have learned and learn how to apply modern technology to the process of mechanical design.

2. Applying the reformed teaching mode, students become interested in the mechanical design course. In addition, teachers can share their research with students in time. Thus, the abilities to analyze and solve problems are improved, and the burden of teachers can be reduced as they guide graduation projects.

3. Implementing the reformed teaching mode, teachers can help enhance the students' practical and application abilities for simulation technology and satisfy the requirements of enterprises for graduates.

Therefore, the reformed mode of mechanical design course is successful, and teaching effectiveness shows that this type of mode should be promoted to other courses.

\section{Acknowledgment}

This work was supported by Postgraduate Education Innovation Program of Shandong Province (Grant No.SDYY15087), First-class Discipline Construction Project of Shandong Province, and Excellent Teaching Team Construction Plan of Shandong University of Science and Technology (Grant No.JXTD20160505).

\section{$7 \quad$ References}

[1] H. G. Xiong. Research on knowledge fusion based teaching method for mechanical design course, China university teaching, 2012, vol. 12, pp. 80-82.

[2] X. B. Le, D. A. William, and J. Michael. The balance of the theory, simulation and projects for mechanical component design course, ASEE Annual Conference and Exposition, Conference Proceedings, 2014.

[3] K. Cohen, R. Katz. Teaching mechanical design practice in academia, Procedia CIRP, 2015, vol. 36, pp. 177-181. https://doi.org/10.1016/j.procir.2015.01.043

[4] P. M. Ostafichuk, H. F. M. Van Der Loos, and J. Machiel. Using team-based learning to improve learning and the student experience in a mechanical design course, ASME international mechanical engineering congress and exposition, Proceedings, 2010, vol. 6, pp. 405-412.

[5] A. Albers, C. Sauter, T. Maier, and J. Ottnad. Academic engineering design education in a realistic environment, Proceedings of the ASME international design engineering technical 
conferences and computers and information in engineering conference 2009, DETC2009, 2009, vol. 8, pp. 565-573. https://doi.org/10.1115/detc2009-87425

[6] G. H. Xu, W. L. Chen, P. F. Sun, and H. B. Wan. Application of MATLAB interactive simulation in teaching of mechanical design, Journal of Zhejiang University of Water Resources and Electric Power, 2014, vol. 26(1), pp. 82-86.

[7] G. Beckmann, D. Krause. Machine part exhibition and functional mock-ups to enrich education, ICED11-18th International Conference on Engineering Design - Impacting Society through Engineering Design, 2011, vol. 8, pp. 130-139.

[8] K. Andersson. Using model-based design in engineering design education, Proceedings of the ASME Design Engineering Technical Conference, 2012, vol.7, pp. 69-76. https://doi.org/10.1115/detc2012-71081

[9] G. Beckmann, and D. Krause. Improving the mechanical design education by hands-on experience with machine parts, DS 62: Proceedings of E and PDE 2010, the 12th international conference on engineering and product design education - when design education and design research meet, 2010, pp. 592-597.

[10] M. Fujii, N. Kato, T. Shimizu, K. Satomi, and S. Taguchi. Cooperation between an enterprise and a school in mechanical design education by using 3D-CAD, Nihon Kikai Gakkai Ronbunshu, C Hen/Transactions of the Japan Society of Mechanical Engineers, Part C, 2007, pp. 30-35.

[11] X. Y. Li, N. N. Wang, Y. G. Lv, Q. L. Zeng, and K. Hidenori. Tooth profile modification and simulation analysis of involute spur gear, International Journal of Simulation Modeling, 2016, vol. 15(4), pp. 649-662. https://doi.org/10.2507/IJSIMM15(4)6.358

\section{Authors}

Xeuyi Li (corresponding author) is an associate professor in College of Mechanical and Electronic Engineering, Shandong University of Science and Technology, Qingdao, 266590, China. He is a member of China Computer Federation (CCF) (lixueyi07@tsinghua.org.cn).

Junying Wei is a lecturer in College of Mechanical and Electronic Engineering, Shandong University of Science and Technology, Qingdao, 266590, China (jdwjy0726@163.com).

Shuhui Ding is an associate professor in College of Mechanical and Electronic Engineering, Shandong University of Science and Technology, Qingdao, 266590, China(shdingcn@163.com).

Quanwei Wang is a professor in College of Mechanical and Electronic Engineering, Shandong University of Science and Technology, Qingdao, 266590, China. He is the executive director of the research institute of exchangeability and measurement technology in Chinese universities (wqw79279@163.com).

Article submitted 29 May 2017. Published as resubmitted by the authors 03 July 2017. 